\title{
The Dramatic Spread of Diabetes Mellitus Worldwide and Influence of Helicobacter pylori
}

Salwa AM Nasrat ${ }^{1}$, Randa M Nasrat ${ }^{2}$, Mohammad M Nasrat ${ }^{2}$, Mohammad A Ibrahim ${ }^{3}$ and Abdullah M Nasrat ${ }^{4,5,6^{*}}$

${ }^{1}$ Department of Physical Therapy, Cardiac Surgery Academy, Cairo, Associate Research Therapist., Egypt

${ }^{2}$ Department of Internal Medicine, Helwan General Hospital, Helwan, Internist, Egypt

${ }^{3}$ Medical Service, Saudi Airlines Catering, Research Fellow, Saudi Airlines Medical Service, Jeddah, KSA

${ }^{4}$ Department of Surgery, Balghsoon Clinic, Jeddah, KSA

${ }^{5}$ Department of Genomic Medical Research, King Fahad Research Center, KAAU, Jeddah, KSA

${ }^{6}$ Department of Surgery, KAAU, Jeddah, KSA

"Corresponding author: Abdullah M. Nasrat, General Surgeon, Department of Surgery, Balghsoon Clinic, Jeddah, Research fellow, Department of Genomic Medical Research, King Fahad Research Center, KAAU, Jeddah, Research fellow, Department of Surgery, KAAU, Jeddah, KSA, Tel: + 966 (012) $6673645 ;$ Fax: + 966 (012) 667 3645; E-mail: abdullahalnasrat@yahoo.com

Rec date: July 04, 2014, Acc date: Nov 14, 2014, Pub date: Nov 21, 2014

Copyright: ( $) 2015$ Nasrat SAM, et al. This is an open-access article distributed under the terms of the Creative Commons Attribution License, which permits unrestricted use, distribution, and reproduction in any medium, provided the original author and source are credited.

\begin{abstract}
Objective: Demonstration of an influence of Helicobacter pylori in the dramatic spread of Diabetes mellitus (DM) among many patients during the last two decades.

Background: The flare up of a lot of medical challenges related to $H$. pylori through immune or different unknown reasons made the medical world believe that $H$. pylori eradication should be a necessary attempt. These $H$. pylorirelated medical problems are sufficient to render the matter that $H$. pylori can reside hidden somewhere in the body be taken seriously. The spread of DM is rising in a dramatic way as the fire spreading in hey especially in developing countries giving the term "diabetic epidemic" an actual credibility. H. pylori could migrate or get forced to migrate to the colon leading to accumulation of profuse toxic amounts of ammonia unopposed or buffered by any acidity leading to biological stress to the body that could predispose to stress diabetes among disadvantaged susceptible people.
\end{abstract}

Design: Prospective study.

Setting: Balghsoon Clinic, Jeddah, Saudi Arabia.

Patients \& Methods: 18 cases of newly discovered DM associated with a definite history of $H$. pylori dyspepsia were included in this study. The study was held in Balghsoon Clinic in Jeddah during the period between May, 2011 and October, 2013. Traditional measures were used for the relief of dyspeptic symptoms, eradication of $H$. pylori, colon care and colon clear.

Results: All patients expressed dramatic relief of their dyspeptic symptoms and the diabetic condition has been successfully and permanently corrected in 16 patients.

Conclusion: In the light of the accurate determination of recent findings and statistics, a revision of the current guidelines for the management of $H$. pylori and newly discovered DM may be needed. It may be incorrect that the current world's burden of DM is on the account of type II diabetes. It seems that the antibiotic violence has obliged a domestic bug to become wild in sequels instead of getting rid of it.

Keywords: Diabetes mellitus; Helicobacter pylori; Stress diabetes

\section{Introduction}

The widespread prevalence and the challenges constituted by Helicobacter pylori; namely its close relation to acid peptic disease, gastric carcinoma and lymphoma have led to the widely-established medical concept that $H$. pylori eradication should be a necessary attempt. Although eradication regimens do eradicate $H$. pylori from the stomach; the emergence of antibiotic-resistant $H$. pylori strains, the severe side effects and the high costs are major drawbacks of these treatments [1]. More efficient, economic and friendly drugs need to be developed.

The latest reports in literature demonstrate a definite flare up of many medical challenges strictly related to $H$. pylori existence through immune or different unknown reasons. Autoimmune thyroiditis, autoimmune pancreatitis, idiopathic thrombocytopenic purpura and acute inflammatory demyelinating polyradiculoneuropathy (GuillianBarre Syndrome) are examples of these challenges [2]. The flare up of these $H$. pylori-related medical challenges is sufficient to denote that 
the current combined antibiotic eradication strategies are inadequate to control all the problems associated with the stomach bug.

$H$. pylori colonized the stomach since an immemorial time [2] as if both the stomach and the bug used to live together in peace, harmless to each other.

\section{Patients and Methods}

The scientific interest of this study was focused on the pathologic effect of $H$. pylori in leading to an onset of diabetes. The study was held in Balghsoon Clinic in Jeddah, Saudi Arabia, during the period between May, 2011 and October, 2013. 18 cases of newly discovered DM associated with a definite history of $H$. pylori dyspepsia were randomly included in the study once the onset of diabetes was recognized without any selection. The protocol of the study has been approved by the institutional review board of King Abdul-Aziz University Hospital in Jeddah, Saudi Arabia. An informed signed consent has been obtained from all patients.

Screening of patients for existence of $H$. pylori was based on clinical symptoms and detection of $H$. pylori serum antibodies. A brief history suggestive of $H$. pylori abnormal behavior was taken, the following dyspeptic symptoms; epigastric discomfort, heart burn, abdominal distension and constipation were considered. Detection of $H$. pylori serum antibodies, though non-specific, was used for screening as being cost-effective [3]. Existence of $H$. pylori was confirmed by reliable specific and sensitive tests; $H$. pylori fecal antigen and urea breath tests $[2]$.

The $H$. pylori serum antibodies test was available from Semen Co., USA with Batch No. 104132 while the urea breath test was available from Helicap Co., Sweden with Batch No. HCO1150108-E10. The $H$. pylori fecal antigen test was obtained from Acon Laboratory, USA, Batch No. HP8040008.

Detection of raised random blood sugar samples in three successive days was the criterion to include cases in the study, while recovery from diabetes after eradication of $H$. pylori was not considered before a normal blood sugar curve was achieved.

All patients were middle-eastern citizens, living in a developing country life style and health care standards. Age of patients ranged between 30 and 45 years, they were average to well-built and one of them was overweight. Five patients were having a positive family history of DM; the one with overweight was not having any family history of diabetes. The random blood sugar level upon inclusion of patients in the study ranged between 270 to $330 \mathrm{mg} / \mathrm{dl}$.

Frequency of micturition was a constant feature in all patients and all of them were confirmed positive for $H$. pylori existence by reliable sensitive laboratory tests ( $H$. pylori fecal antigen and urea breath tests). None of the patients was undergoing any recent reason of physical or emotional stress, and they were not suffering from any other grave or debilitating illness.

Traditional measures, colon care and colon clear were employed for all patients for the relief of the dyspeptic symptoms and eradication of H. pylori $[2,4]$.

A diabetic diet was strictly followed, and extreme carefulness towards re-infection with $H$. pylori via oral intake during the eradication therapy by avoiding outside-home meals was seriously needed. The potent senna purge was employed for colon clear while a vinegar-mixed yoghurt taken as a salad during meals after colon clear was used to behave or get rid of the abnormal behavior gastric $H$. pylori strains. The senna purge and the vinegar therapy were essentially an outpatient treatment. The initial vinegar therapy consisted of two table spoonful of 5\% white vinegar mixed with a small cup of plain yoghurt and taken twice daily during meals for one week.

Successful eradication of $H$. pylori was assessed by the $H$. pylori fecal antigen and urea breath tests.

Colon clear, repeated every month with gradual reduction of the dose, was followed during the period of study; while colon care with vinegar-mixed food taken once or twice daily, three to five days a week was considered as a life style during the follow up of patients.

A similar group of patients nearly of similar size (17 patients) who decided to follow oral medical treatment from the start was considered as a control group. They were also of an onset of newly discovered DM with age range of 33-41 years, average built and a random blood sugar of $250-290 \mathrm{mg} / \mathrm{dl}$. They were having no other chronic illness or a family history of diabetes.

\section{Result}

All patients of the colon therapy group became free of any dyspeptic or micturition symptoms, 12 patients (66.7\%) resumed a normal blood sugar curve in less than one week. The one with overweight and the five patients with family history of DM were among them. The diabetic condition did not recover until 10-13 days in 4 patients (22.2\%). The glycated hemoglobin (HbAlc) for the above patients ranged between $4.8-5.9 \%$ without having any anti-diabetic medical treatment. Failure of follow-up of the case occurred in two patients (11.1\%); their diabetic condition did not improve until 2 weeks of therapy, they decided to follow oral medications.

The patients who recovered the diabetic condition were followed up for 18 months; they did not show any recurrence of diabetes.

The records of the control group patients were followed for three months. They remained inadequately controlled in spite of medications; the $\mathrm{HbAlc}$ was always above $7.0 \%$.

\section{Discussion}

DM in developing countries has been lately described as the fire when spreads in hay; giving the title "diabetic epidemic" an actual credibility [5]. Traditional risk factors do not appear fully sufficient to explain this dramatic spread of diabetes in these countries; in a way that further indicates that the traditional measures employed to control the spread of the disease would never be adequate or decisive.

The current study has developed a general impression that the illdecisiveness and the obvious length of the current $H$. pylori eradication treatment courses allowed the chance to the stomach bug to mutate and develop drastic or resistant strains. In addition, the aggression made by antibiotics could have forced this bacterium to hide or migrate where it could influence or compromise the immune system. This impression is being supported by the fact that tonsils and adenoids have been recently discovered as secondary reservoirs for $H$. pylori $[2,6]$.

DM which was once considered a disease of the developed world has become a worldwide pandemic, resembling an ocean wave flooding the whole world with two thirds of the diabetic population living in the developing side of the globe $[7,8]$. As much as the precise statistical revision strongly correlates between the prevalence of $H$. 
pylori and the flare up of DM in developing countries, it also reveals that the diabetic challenge was not as such in these countries before attacking the bug with antibiotics [7-12].

A lot of controversy has been encountered as concerns the current strategies for $H$. pylori eradication. The efficacy of $H$. pylori eradication strategies, the appropriate length of treatment and the cost effectiveness, all appear controversial [13-16]. Further reports in literature have devaluated the triple therapy and suggested a quadruple one [17]

H. pylori recurrence; whether it is gastric recurrence from dental plaques, fecal-oral recurrence or recurrence via oral intake, is hardly avoidable [18]. The current antibiotic therapies appear to be successful only in forcing $H$. pylori outside the stomach to recur later or migrate and hide elsewhere mostly in the colon. The migrated $H$. pylori strains in the colon would continue producing ammonia for a reason or no reason leading to accumulation of profuse toxic amounts of ammonia, un-opposed or buffered by any acidity; this constitutes a biological stress to the body that could lead to stress diabetes. Administration of traditional oral hypoglycemic pills to a stressed pancreas means an insistence to flog a tired horse leading to turn a potential condition into an established chronic illness with consequent dramatic flare up of the diabetic phenomena.

Dietary vinegar (acetic acid 5\%) has been recently shown to be an effective and decisive measure for the clinical eradication of $H$. pylori infection with an immediate dramatic relief of patient's symptoms [4,19-21]. The complex nutritional requirements of $H$. pylori are achieved mainly via utilization of pyruvate. As acetate is demonstrated as an end product among the metabolic pathway of $H$. pylori and the activity of the pyruvate dehydrogenase complex is controlled by the rules of product inhibition and feedback regulation; this means that addition of acetic acid to the medium could compromise the energy metabolism of $H$. pylori, or interfere with the organism's respiratory chain metabolism [22-26].

As long the matter includes interference with the energy metabolism and the respiratory chain metabolism of $H$. pylori; an immediate paralysis of the organism can be considered, which explains the dramatic immediate symptomatic relief expressed by patients included in this study upon having a vinegar-mixed food. This decisive influence of acetic acid on the activity of $H$. pylori allows no chance for the organism to resist the treatment, mutate and develop resistant strains or even get the opportunity to migrate.

Clearing of the colon was considered the integral element of this natural therapy for elimination of all the migrated colonic $H$. pylori strains in order to help recovery of a potential diabetic condition that developed consequent to a stressful toxic colonic error.

Follow up of patients of the study was extended to 18 months as those patients are susceptible disadvantaged population and they are liable for recurrence of the diabetic condition in consequence to colonic troubles. They have to keep watching their out-side home meals and their colonic condition; they should return to colon clear and regular vinegar therapy whenever they develop any dyspeptic troubles associated with micturition symptoms. They are expected to tolerate and overcome their susceptibility to this toxic biological stress with repeated colon care/colon clear and maintaining carefulness about their colonic condition.

The records of the control group of patients were followed for three months only because they were considered as being candidates of already established diabetes. This could refer to the concept that administration of oral hypoglycemic pills in newly discovered diabetes without ruling out an underlying stress element might constitute a therapeutic malpractice.

\section{Conclusion}

In the light of the accurate determination of recent findings and statistics, a revision of the current guidelines for the management of $H$. pylori and newly discovered DM may be needed. It might be incorrect that the current world's burden of DM is on the account of type II diabetes. It seems that the antibiotic violence has obliged a domestic bug to become wild in sequels instead of getting rid of it. The stress element considered in this study in leading to an onset of diabetes is not just hypothetical as upon the basis of this concept the diabetic condition has been successfully and permanently corrected in most patients of the study. The patients included in this study should be considered susceptible predisposed individuals and they are liable for recurrence; they should keep watching their meals, their colonic condition and they should return to colon care and colon clear whenever they develop any dyspeptic symptoms.

\section{References}

1. Volk WA, Gebhardt BM, Hammarskjold ML, Kadner RJ (1996) Essential of Medical Microbiology. Lippincott - Raven 5th Ed: 377.

2. Farinha P, Gascoyne RD (2005) Helicobacter Pylori and MALT Lymphoma. Gastroenterology 128: 1579-1605.

3. Garcia-Altes A, Jovell AJ, Serra-Part M, Aymerich M (2000) Management of Helicobacter Pylori in duodenal ulcer: a costeffectiveness analysis. Aliment Pharmacol Ther 14: 1631-1638.

4. Nasrat AM (2009) The world misconception and misbehavior towards Helicobacter Pylori is leading to major spread of illness. The 7th AntiAging Medicine World Congress, Monte-Carlo, Monaco.

5. Al-Nozha MM, Al-Maatouq MA, Al-Mazrou YY, Al-Harthi SS, Arafah MR et al. (2004) Diabetes mellitus in Saudi Arabia. Saudi Med J 25: 1603-1610.

6. Cirak MY, Ozdek A, Yilmaz D, Bayiz U, Samim E, et al. (2003) Detection of Helicobacter Pylori and its CagA gene in tonsil and adenoid tissues by PCR. Arch Otolaryngol Head Neck Surg 129: 1225-1229.

7. Katulanda P, Sheriff MH, Matthews DR (2006) The diabetes epidemic in Sri Lanka-a growing problem. Ceylon Med J 51:26-8.

8. Wissow LS (2006) Diabetes, poverty and Latin America. Patient Educ Couns 61: 169-70. Epub.

9. Hossain P, Kawar B, El Nahas M (2007) Obesity and diabetes in developing world-a growing challenge. N Engl J Med 356: 213-215.

10. Einecke D (2006) Like a tsunami: diabetes wave floods the whole world 148: 4-6

11. Yach D, Stuckler D, Brownell KD (2006) Epidemiologic and economic consequences of the global epidemics of obesity and diabetes. N Med 12: 62-66.

12. Narayan $K$, Zhang $P$, Williams D, Engelgau M, Imperatore G, et al (2006) How should developing countries manage diabetes? CMAJ 1757: 733.

13. McColl K, Murray L, el-Omar E, Dickson A, El-Nujumi A, et al. (1998) Symptomatic benefit from eradicating Helicobacter Pylori infection in patients with nonulcer dyspepsia. N Eng J Med 339: 1869-1874.

14. Laheij RJ, Van Rossum LG, Verbeek AL, Jansen JB (2003) Helicobacter Pylori infection treatment for nonulcer dyspepsia: An analysis of metaanalysis . J Clin Gastroenterol 36: 315-320.

15. Ikeda S, Tamamuro T, Hamashima C, Asaka M (2001) Evaluation of the cost-effectiveness of Helicobacter Pylori eradication triple therapy vs. conventional therapy for ulcers in Japan. Aliment Pharmacol Ther 15: 1777-1785. 
Citation: Nasrat SAM, Nasrat RM, Nasrat MM, Ibrahim MA, Nasrat AM (2015) The Dramatic Spread of Diabetes Mellitus Worldwide and Influence of Helicobacter pylori. General Med 3: 1000159. doi:10.4172/2327-5146.1000159

Page 4 of 4

16. Mason J, Axon AT, Forman D, Duffett S, Drummond M, et al. (2001) The cost-effectiveness of population Helicobacter pyroli screening and treatment: a Markov model using economic data from a randomized controlled trial. Aliment Pharmacol Ther 16: 559-568.

17. Songür Y, Senol A, Balkarl A, Bastürk A, Cerci S (2009) Triple or quadripule tetracycline-based therapies versus standard triple treatment for Helicobacter Pylori treatment. Am J Med Sci.

18. McPhee SJ, Lingappa VR, Ganong WF Pathophysiology of Disease, An introduction to Clinical Medicine.

19. Lange Medical Books / McGraw-Hill. 1996; 4th Ed: 361.

20. Nasrat AM (2012) An answer for the controversy of insulin cardioprotection in dysglycemia.
21. Nasrat AM (22013) A topic skin pathology; influence of Helicobacter Pylori and effect combined colon clear with seroclearance therapy.

22. Nasrat AM (2013) An alternative approach for the rising challenge of hypertensive illness via Helicobacter Pylori erdication.

23. Mendz GL, Hazell SL, Burns BP (1993) Glucose utilization and lactate production by Helicobacter Pylori. J Gen Microbiol 139: 3023-3028.

24. Mendz GL, Hazell SL, van Gorkom L (1994) Pyruvate metabolism in Helicobacter Pylori. Arch Microbiol 162: 187-192.

25. Berg JM, Tymoczko JL, Stryer L (2002) Biochemistry. WH Freeman and Company. 5th Ed: 480 .

26. Ge Z (2002) Potential of fumarate reductase as a novel therapeutic target in Helicobacter Pylori infection. Expert Opin Ther Targets 6: 135-146. 